\title{
Tecnología convertida en mito: la obra artística de Eduardo Paolozzi
}

\section{Technology into myth: Eduardo Paolozzi's artistic work}

\author{
Mercedes Aguirre Castro \\ Profesora Contratada Doctora del Departamento de Filología Griega \\ y Lingüistica Indoeuropea de la Facultad de Filología \\ (Universidad Complutense de Madrid)
}

- Artículo invitado -

Fecha de recepción: 9 de diciembre de 2016

Para citar este artículo: Aguirre Castro, M. (2017): Tecnología convertida en mito: la obra artística de Eduardo Paolozzi, Icono 14, volumen 15 (1), pp. 149-165. doi: 10.7195/ri14.v15i1.1038 


\section{MONOGRÁFICO}

\section{Resumen}

Eduardo Paolozzi, un artista británico de origen italiano, inició su carrera artística dentro del llamado Pop Art británico con collages que partían de la cultura popular norteamericana y sus objetos de la vida cotidiana y de sus anuncios y revistas, utilizando monstruos y robots de la ciencia ficción al lado de personajes como Mickey Mouse e imágenes de radios y cohetes espaciales. Posteriormente desarrolló su carrera como escultor produciendo esculturas en bronce, a algunas de las cuales dio nombres de personajes de la mitología clásica (Jasón, Dédalo, Cíclope). Estas esculturas eran creadas a partir de un conglomerado de partes de máquinas y desechos que luego fundía en bronce. Las figuras resultantes reflejan el interés del artista por la idea de la fusión del hombre y la máquina, aunque al final no son ni hombres ni máquinas. Parte de los objetos que componen estas esculturas proceden de la tecnología de la época (ruedas, transistores, motores) de manera que estos productos tecnológicos se convierten en el material del artista: se trata de una técnica escultórica que se denomina "Brutalismo".

Palabras clave: Paolozzi - Collage - Mitos - Hombre-máquina - Brutalismo - Objects trouvés - Pop Art

\section{Abstract}

Eduardo Paolozzi, a British artist of Italian origin, began his artistic career in the so-called British Pop Art movement with collages derived from North American popular culture, its everyday objects, advertisements and magazines, using monsters and robots from science fiction alongside characters like Mickey Mouse, as well as images of radios and space rockets. Later he developed his career as a sculptor, producing works in bronze, to some of which he gave the names of figures from classical mythology (Jason, Daedalus, Cyclops). These sculptures were created from a conglomerate of parts of machines and rubbish, which he subsequently cast in bronze. The resulting figures reflect the interest of the artist in the idea of the fusion of man and machine, although in the end they are neither men nor machines. Some of the objects which constitute these sculptures come from contemporary technology (radios, transistors, motors), so that these technological products become artists' materials: this is a sculptural technique known as Brutalism.

Key Words: Paolozzi - Collage - Myths - Man-machine - Brutalism - Objects trouvés - Pop Art 


\section{Introducción}

La idea de una figura inanimada que puede moverse y comportarse como si tuviera vida aparece ya en la antigüedad clásica. La mitología nos ofrece algunos ejemplos: el caso quizá más conocido es el del mito de Pigmalión (0vidio, Metamorfosis 10. 243-297) quien, enamorándose de una estatua de su propia creación, consigue que la diosa Afrodita le de vida convirtiéndose en una hermosa joven (la que a partir del siglo XVIII será llamada Galatea). Sin embargo, este ejemplo lleva la definición de automaton (palabra griega con el significado de "con movimiento propio") a un grado insostenible ya que la estatua no se convierte en una máquina que imita la vida sino en una completa mujer viviente (Kang 2011,16). Por otro lado, la Ilíada (18. 376-377) documenta la existencia de dos figuras hechas de bronce fabricadas por Hefesto que actúan como si tuvieran vida y trabajan como servidores del dios en su palacio y en las Argonáuticas de Apolonio de Rodas aparece un gigante de la raza de bronce, Talos, que guarda la isla de Creta y que será vencido gracias a las artes de hechicería de Medea. Este gigante es concebido por Apolodoro (Biblioteca 1.9.26) como un autómata. Otro personaje de la mitología clásica asociado con los autómatas es Dédalo, quien fue famoso por construir estatuas vivientes (este y otros ejemplos comentados en Kang 2011, 16-20).

La obra de Herón de Alejandría (ca. 62 AD) Pneumatica demostraba la posibilidad de construcción de maquinarias en forma de figuras humanas y animales que, mediante principios mecánicos o movidas por el agua, podía parecer que tenían vida propia. Este tipo de mecanismos fueron redescubiertos en el Renacimiento y llevados a figuras que adornaron célebres jardines y grottos como los de Pratolino en las afueras de Florencia. Estos autómatas que podían realizar toda una serie de movimientos como si estuvieran vivos servían fundamentalmente para sorprender y deleitar a los visitantes de los jardines (Jeanneret 2001, Nelson 2001, 2-3, 50).

El autómata, como objeto real y como idea, ha perdurado a través de los siglos con creciente fuerza debido a la fascinación que siempre ha producido en el hombre la idea de una máquina que pretende ser un hombre (o un animal) con todas sus funciones y que desafía la distinción entre lo vivo y lo muerto, lo animado y lo inanimado y lo natural y lo artificial. Como objeto conceptual el autómata fue 


\section{MONOGRÁFICO}

utilizado en varios campos de investigación en el siglo XVII (Kang 2011, 116) (Un recorrido por la historia de los autómatas lo encontramos en Kang 2011, GlaserRossbach 2011). El autómata ha servido también como metáfora para el estado, el mundo o el mismo cuerpo humano. En la era industrial aparece la asociación de la máquina con el poder, una imagen que persiste hasta nuestros días.

Por otro lado, los autómatas han tenido impacto en la literatura con, por ejemplo, el relato de E.T.A. Hoffmann "El hombre de arena" (1816) que presenta una representación mecánica de un ser humano en la muñeca que canta, Olimpia, de tamaño natural; o el de Edgar Allan Poe "El jugador de ajedrez de Maezel" (1836), una historia sobre un fraudulento autómata jugador de ajedrez que se hizo famoso en la época (Kang 2011, 178), una historia que anticipa alguno de los motivos de la ciencia-ficción. Asimismo en el siglo XIX tendríamos el bien conocido ejemplo del personaje del monstruo de Frankenstein en la novela de Mary Shelley Frankenstein o el moderno Prometeo que es considerada generalmente como la primera obra de ciencia ficción de la literatura, aunque en este caso no se trata de un autómata mecánico sino de un ser construido artificialmente a partir de diversos trozos de cadáveres. Otro ejemplo es el relato del norteamericano Ambrose Bierce El maestro Moxon publicado en The San Francisco Examiner en 1899 y que emplea la palabra "robot" por primera vez en su descripción de un autómata que juega al ajedrez y que termina por asesinar a su creador.

Ya a finales del siglo XIX y principios del XX la modernidad se entiende como una proliferación de los mecanismos automáticos que dan lugar a una particular atención por los aspectos del dinamismo espaciotemporal y su impacto en las distintas manifestaciones culturales, según señala Susan Buck-Morss $(2002,63)$ y que toman cuerpo en la figura del hombre-máquina. El género de la ciencia ficción introduce entre sus temas la figura del autómata o robot. Se trata de una máquina parecida físicamente a un ser humano que puede replicar determinados movimientos y funciones humanas automáticamente. Mientras que para unos la mecanización forma parte de los nuevos ritmos urbanos que quedan reflejados en las nuevas poéticas urbanas, para otros la vida autómata presenta sus peligros, como ocurre en la obra del cineasta alemán Fritz Lang Metrópolis (1927), donde la revolución viene incitada por un robot que lidera a los obreros que viven en un gueto subterráneo sin poder salir al exterior (Nelson 2001, 210-261, Kang 2011, 268). 
La palabra robot fue usada por primera vez en 1920 por un escritor checo, Karel Čapek, pero en realidad fue su hermano el auténtico inventor del término. Los primeros robots electrónicos autónomos fueron creados por William Grey Walter en Bristol en 1948 y en el año 1954 se construyó en Estados Unidos el primer robot programado inventado por George Devol. Estos autómatas-robots empezaron a aparecer en el género de la ciencia-ficción, bien como seres procedentes de otros planetas con tecnologías más avanzadas que las nuestras o como figuras que terminan rebelándose contra los humanos que los crearon, como en el caso que he mencionado. En muchas de estas historias en ocasiones lo que era solo una máquina se convierte en un monstruo que genera un peligro para los humanos. Los robots empiezan también a ser representados en el arte, en imágenes que poseen un lado más siniestro en la idea de que un humano deshumanizado es como una máquina (Kang 2011, 276). El tema de la destrucción de la humanidad como consecuencia del desarrollo de seres artificiales alcanza su punto álgido con la publicación en 1968 de 2001: Una odisea espacial de Arthur C. Clarke, escrita en paralelo a la versión cinematográfica dirigida por Stanley Kubrick. El robot aparece también como símbolo de conformismo humano y deshumanización. En definitiva, la historia del conflicto de la humanidad con las máquinas por el dominio del mundo es un cliché de nuestro tiempo de la literatura y el cine de ciencia ficción.

En esta línea de experimentación con el hombre-máquina se enmarca el trabajo del artista británico Eduardo Paolozzi, en cuyas obras se inscribe la relación entre lo epistemológico y lo tecnológico, que este artículo explora y que surge de los aspectos semióticos de determinados elementos que aparecen en sus obras, como es el caso de la rueda, cuyo significado simbólico en el marco del desarrollo de la civilización y la tecnología es innegable, o el martillo que, asociado al dios de la fragua, Hefesto, también tiene connotaciones que se refieren al trabajo humano y a la tecnología. Junto a estos elementos se sitúa el contexto social que rodeó al artista, con acontecimientos tan importantes como la carrera espacial que culminaría en la llegada a la luna de la misión soviética en 1959 y de la norteamericana en 1969. Paolozzi planteó un fructífero diálogo sobre el tema “hombre versus máquina", tema relevante todavía hoy, examinando a través de su obra las áreas de dominio e influencia entre los dos, cuando el uno o el otro asume el papel de amo 0 siervo. 


\section{MONOGRÁFICO}

\section{Metodología}

Este trabajo se coloca en el contexto de los estudios de mito-análisis y mitocrítica en relación con los cambios tecnológicos, con el fin de estudiar las adaptaciones de los mitos y su presencia en el mundo contemporáneo. En la introducción al volumen Nuevas formas del mito (2015), José Manuel Losada presenta la problemática del análisis mitocrítico cuyos orígenes se remontan a Las estructuras antropológicas del imaginario, estudio del antropólogo francés Gilbert Durand (1981) que da cuenta de la importancia del imaginario colectivo en la creación y proyección de los mitos en la cultura contemporánea. En la sociedad moderna, sumida en hábitos de consumo que siguen ritmos vertiginosos, lo material y lo imaginario interactúan en una retroalimentación de proyecciones semiótico-simbólicas asociadas a los objetos que nos rodean: son esos "objetos encontrados" (objects trouvés), muchos de ellos relacionados con la tecnología del hombre-máquina y del autómata, sobre los que Paolozzi reflexiona, reimaginando y recreando con ellos los personajes de los mitos clásicos. Aunque Paolozzi paradójicamente da la vuelta a la idea del autómata como objeto inanimado que posee la capacidad del movimiento: lo que crea son figuras que parecen autómatas pero que al final son estatuas inmóviles, como suspendidas en el tiempo. Asimismo, el artículo explora la vinculación de Paolozzi con el Brutalismo, una corriente artística que tuvo gran importancia entre $1950 \mathrm{y}$ 1970. Aunque esta se relacionó fundamentalmente a la arquitectura, inspirada en los trabajos del arquitecto suizo Le Corbusier. Paolozzi s unió a este movimiento al utilizar materiales que incluían productos en bruto (de ahí derivó el término Brutalismo), es decir, desechos de máquinas, ruedas y otros productos industriales y tecnológicos.

\section{Discusión}

Eduardo Paolozzi nació en Edimburgo en 1924, de padres italianos. Fue un artista de muy ricas y variadas formas. Sus primeras influencias proceden de Matisse y Picasso y, más tarde, de Paul Klee. También se vio profundamente influido por el Dadaísmo y el Surrealismo en la época en que vivió en París. Posteriormente, en 1952 y ya en Londres, fue fundador del llamado "Grupo independiente" que es con- 
siderado como precursor de los movimientos del Pop Art que prestaban más atención al arte "inferior" y a la cultura popular, sobre todo americana. Así Paolozzi va a ser conocido como artista en esa época de los años 50 sobre todo por sus collages de imágenes y palabras cortadas de revistas de entonces que él adaptó a los medios impresos. Estos collages fueron considerados importantes representaciones del Pop Art (Bermúdez Dini 2011, 332-3), concretamente del llamado Pop Art británico, término acuñado por primera vez por el crítico de arte Lawrence Alloway en 1954. El propio Alloway fue miembro del Grupo Independiente y utilizó el término Pop no para describir un estilo de arte, sino para describir productos creados para un público de masas (Collins 2014, 96).

La cultura de masas es, por tanto, el punto de partida de Paolozzi cuyas ideas artísticas en este momento se fundamentan en un mundo de imágenes reproducidas mecánicamente, en revistas, en el cine, en los anuncios, es decir, en los medios de la civilización moderna. El sujeto de este estilo de arte Pop es, por tanto, el ambiente urbano en sus cualidades cotidianas. Este tipo de obra que consistía en recortes de revistas y anuncios ya la comenzó Paolozzi al principio de su carrera, por ejemplo en "Sack-o-sauce" de 1948 en el que Minnie Mouse se tira de cabeza en una lata de salchichas 0scar Mayer, producto que se introdujo por primera vez en 1946 vendiéndose ya con la salsa; otros elementos de esta obra hacen referencia a la obra de Joan Miró. Ya en los años 50 produjo “Was the monster Master or Slave?" (1952) en el que introduce al monstruo-robot de la ciencia ficción que veremos después repetidamente en su obra y que muestra su temprano interés por ese género popular. Otro ejemplo en la misma línea es el collage "The Ultimate Planet" (1952) también realizado a partir de revistas y comics de ciencia ficción. Luego desarrolló este estilo sobre todo a finales de los años 60 y 70 en obras con una gran influencia de la cultura popular norteamericana (que de ahí recibió el nombre de Pop). Para estas obras usó fotos con imágenes de artistas y películas de Hollywood de la época, incluyendo a Marilyn Monroe, al Pato Donald o Mickey Mouse, o imágenes relacionadas con máquinas, cohetes espaciales, robots o monstruos del espacio que aparecían en los comics y novelas de ciencia ficción de la época. Por otro lado, también utilizó imágenes de objetos representativos de la época como el transistor, lo que representa una respuesta visual a su reciente invención. A comienzos de 1962 Paolozzi creó numerosas obras impresas (las llamadas screen prints o silk screens) 


\section{MONOGRÁFICO}

incorporando material de ilustraciones de libros científicos, catálogos, anuncios de películas, revistas, cómics y anuncios de todo tipo. Por ejemplo, "Moonstrips Empire News" (1967) que consistía en una caja con materiales en lo que parece una ordenación al azar: textos y fotos que el espectador puede arreglar según sus intenciones. En estas obras los colores cuidadosamente delineados sirven para distinguir las partes individuales de la obra. Así contrastan más claramente unas con otras y emergen con más fuerza como elementos de collage. Otros ejemplos de esta misma técnica -que de alguna manera tienen ya el estilo de los gráficos de ordenador- serían: “General Dynamic F.U.N. (1970) y “BASH” (1971).

\subsection{Palozzi y la mitología clásica}

Los orígenes del interés de Paolozzi por el collage se encuentran en el Dadaísmo. Le impresionaron los collages de Francis Picabia o Max Ernst, y de ellos y otros Dadaístas Paolozzi toma la idea de incluir fragmentos banales de la realidad. De esta misma fuente de inspiración procede su predilección por los objects trouvés "objetos encontrados". Paolozzi se sentía orgulloso de pertenecer a una cultura que no tiraba nada y salvaba cosas para un posible uso futuro. El artista se apropiaba de materiales efímeros que estaban ahí para ser reutilizados. Pero Paolozzi transforma esos "objetos encontrados" hasta tal punto que ya no son reconocibles inmediatamente. Estas imágenes contribuyeron a formular un lenguaje visual para acompañar una cultura popular que alcanzó la categoría de mítica: personajes y objetos, mitos de nuestro tiempo, expuestos como parte de la obra de arte, de manera que se vuelven imperecederos. El autor los sitúa también nivel de otros motivos recurrentes de siglos precedentes en la historia del arte, incluyendo temas de la mitología clásica.

El primer acercamiento de Paolozzi a la mitología clásica se remonta a los collages, concretamente a unos para los que tomó ilustraciones en blanco y negro de escultura clásica y les colocó encima recortes de un manual sobre motores. Así fueron realizados "Head of Zeus" (1946) y "Head of Demeter" (1946). La razón de su interés en trabajar con esculturas clásicas procede de su carácter roto y fragmentario ya que para Paolozzi esa cualidad les daba más posibilidades creativas (Collins 2014, 26-27). Por otro lado, estas imágenes son el comienzo de su interés 
por la idea de la fusión del hombre y la máquina, un interés por crear figuras que combinaban aspectos y rasgos humanos con otros propios de las máquinas y de la industria, en una unión en la que no se puede distinguir cuál es el hombre y cuál es la máquina.

Paolozzi realizó también esculturas en bronce, un material que era menos perecedero y entre ellas encontramos unas a las que el artista tituló con nombres de la mitología clásica. En una época en la que en Gran Bretaña el modelo dominante de escultura era el clasicismo de Henry Moore, Paolozzi aparece como una ruptura con ese estilo porque él pensaba que era necesario volverse hacia los artistas europeos -Picasso, por ejemplo- para ser original (Stonard 2011, 17). Así crea esculturas hechas de un conglomerado de partes de máquinas y desechos que luego fundía en bronce. La técnica del collage se transfiere de esta forma a la escultura.

Una de sus mejores esculturas es "Jason", de 1956, que se encuentra en el MOMA de Nueva York. Al parecer esta escultura le fue inspirada por el personaje de Jasón en el ballet "Medea" de 1947 de Samuel Barber. Paolozzi sigue el ejemplo de Barber y ha intentado hacer una figura que existe a la vez en dos épocas: la antigua y la contemporánea, una figura que tiene algo de la curva sinuosa que se daba a las esculturas de desnudos clásicos griegos, pero sus piernas son cilindros parcialmente abiertos y su torso y su cabeza están fusionados en una única forma (Collins 2014, 113). Una pequeña rueda cuelga de su torso en el lugar de los genitales. Aunque tenga la apariencia de una figura frágil y estropeada, sin embargo produce una sensación de gran resistencia.

Las otras figuras que aluden específicamente a figuras míticas griegas son "Ícaro" (1949) de la que hizo otra versión en 1957 y dos "Cíclope" (en la Tate Gallery de Londres). El segundo "Ícaro" (en la National Gallery of Modern Art en Edimburgo) es probablemente la figura más angulosa de Paolozzi, cuya superficie es una variada mezcla de bultos rudimentarios que parece más un saco de patatas y cuyos brazos/ alas están hechos de trozos de madera. En opinión de Judith Collins, lo más probable es que el interés de Paolozzi por este personaje no fuera para mostrar un ejemplo del final trágico de la hybris humana, sino por el hecho de que su historia tiene que ver con la cera que se derrite, lo que ocurre exactamente en el proceso de crear una 


\section{MONOGRÁFICO}

figura de bronce (en la técnica llamada "cera perdida": Collins 2014, 113-114). En cuanto a los dos "Cíclope", uno es una figura humana completa, desnuda y sin brazos, mientras que el otro es solo una cabeza. Ambas fueron realizadas en 1957. La figura completa no es muy grande, es una figura de pie, como de un metro de alto, está realizada en bronce con un amasijo de detritus, por detrás tiene un aspecto más humano y liso. Estas dos esculturas están realizadas con un conglomerado de partes de máquinas y objetos de desecho, en la figura de cuerpo entero el único ojo del cíclope parece estar representado por una rueda con radios. Otra rueda con radios aparece en el lugar de los genitales masculinos. Y adelantamos aquí que el motivo de la rueda es un tema recurrente en toda su carrera, incluso tiene una obra que se llama "Her Majesty the Wheel" (1958-59) que tiene una rueda por cabeza.

Por otro lado, la cabeza de "Cíclope" es de un color más amarillento, con una pátina dorada, y presenta por delante un amasijo de elementos mientras que es completamente lisa por detrás, en su parte frontal tiene dos agujeros pequeños, uno arriba -quizá representando el ojo único de esta figura mitológica- y otro más abajo, como una boca. El cíclope de cuerpo entero podría pasar por un ser de otro mundo, de otro planeta, tal vez escapado de las páginas de uno de esos libros y revistas de ciencia-ficción que él disfrutaba leyendo. Sería un hombre transformado en una máquina, una idea -la del hombre y la máquina- que, según las palabras del propio Paolozzi y como ya hemos comentado, fue un tema especialmente recurrente en gran parte de su obra (Paolozzi 1979, 12).

Estas imágenes-cosas (él decía que se convirtió en escultor porque quería crear "cosas" (Stonard 2011, 17)) compuestas de objetos de desecho (objects trouvés) y con un papel destacado de la rueda y de otros elementos mecánicos nos recuerdan a la obra del artista suizo del Nouveau Réalisme de los años 60 Jean Tinguely. Pero las figuras de Paolozzi no son extrañas maquinarias que se mueven y producen ruidos como las de Tinguely sino figuras generalmente antropomórficas, estáticas que se asemejan a versiones fosilizadas de monstruos de películas de terror o de ciencia-ficción. Este tipo de esculturas que combinan imágenes de dioses, hombres destruidos y robots humanizados se refieren a los eternos héroes de la antigüedad, pero no expresan tanto la idea del antiguo héroe como el concepto del héroe moderno (Kirkpatrick 1970, 27). 
Estas esculturas expresan símbolos arcaicos, y a primera vista parecen producto de una civilización primitiva, como si se acabaran de encontrar en una excavación arqueológica, con restos de la utilización de la técnica de la cera perdida cual polvo de ladrillo y la pátina, como si hubieran estado enterradas durante siglos. Hay que tener en cuenta que en esa época las excavaciones arqueológicas eran descritas regularmente en la prensa. En una reseña a una exposición suya en Hanover se describía el trabajo de Paolozzi como "parecido a una excavación arqueológica vista desde el aire" (Kitnick 2011, 67).

Un aspecto interesante sería la cuestión del título de la obra: llamando a estas esculturas "Cíclope" o "Jasón" o "Icaro" Paolozzi las coloca en una tradición que se remonta a 3.000 años atrás aproximadamente; si las hubiera llamado "Robot" como a otra escultura semejante de 1956 (perteneciente a una colección privada) la habría situado en un contexto muy diferente, de inteligencia artificial y películas sobre el futuro. Se trata de una figura de pie de un hombre-máquina cubierto de una pátina dorada, lo mismo que su cabeza de "Cíclope". Hay que señalar que Paolozzi, lo mismo que otros colegas del ICA incluyendo Alloway y Hamilton, se entusiasmó con dos libros recientes de Norbert Wiener: Cybernetics: or Control and Communication in the Animal and the Machine (1948) y The Human Use of Human Beings (1950), entre 1948 y 49 se publicaron obras sobre el tema de la inteligencia artificial y el propio Wiener acuñó la palabra cibernética para describir las similitudes estructurales entre los sistemas de comportamiento de los seres vivos y los entes mecánicos (Collins 2014, 122). Entre 1948 y 49 William Grey Walter había construido los primeros robots de tres ruedas en Bristol y en 1954 se construyó en Estados Unidos el primer robot programado construido por George Devol al que llamó Unimate (señalemos aquí que muchos de los collages y screen prints de Paolozzi que hemos comentado antes muestran a Unimate o a otro de su especie representado). De alguna manera, esos monstruos de las películas de ciencia ficción $\mathrm{y}$ de terror han reducido las hazañas de los antiguos dioses y héroes a melodrama barato. A través de estas esculturas podemos ver asimismo que el interés del artista está también en los límites del hombre, quizá -como dice Alloway- especulando sobre el futuro de una humanidad que tiene que soportar presiones terribles y a veces extremas. 
MONOGRÁFICO

\subsection{Del hombre-máquina al Brutalismo}

Brutalismo es un término que fundamentalmente se aplicó a la arquitectura, utilizado ya por Le Corbusier, pero que de ahí pasó a designar obras artísticas, esculturas, que presentaban los materiales en bruto. Paolozzi se interesó, como ya hemos dicho, en el uso de materiales que incluían desechos de máquinas, ruedas y otros productos industriales. Hemos visto cómo la rueda formaba parte de la anatomía de su "Jason" o su "Cíclope", en los que una rueda con radios aparece en el lugar de los genitales masculinos. Como ya dijimos, el motivo de la rueda es un tema recurrente en toda su carrera, incluso tiene esa obra ya mencionada titulada "Her Majesty the Wheel" (1958-59) que tiene una rueda por cabeza. Todo esto formaría parte de la técnica escultórica del "Brutalismo" (Highmore 2011, 87-104). Son figuras que parecen versiones fosilizadas de monstruos de películas de terror y ciencia ficción, de manera que aúnan la representación mitológica clásica con imágenes típicas del cine y la cultura de la época. Paolozzi creó una nueva raza de héroes y divinidades; el imaginario mitológico se puso al servicio de la sensibilidad moderna con el uso de materiales destinados a otro propósito, sobre todo materiales que recuerdan las nuevas tecnologías de la época, pero que ya no pertenecen al mundo tecnológico utilizable porque ya no sirven para el propósito para el que fueron creados. Evocan también lo efímero -en los objects trouvés, objetos de desecho, de los que están realizadas- al lado de lo permanente. Unen símbolos arcaicos que traen a nuestra memoria las historias de la mitología clásica junto con elementos perecederos, basura que contiene cosas ordinarias de la vida cotidiana: un transistor roto, una rueda perdida. Simbolizan la relación entre el hombre y la máquina, pero, al final, son figuras en ruinas que no son hombre ni máquina, son como restos de una arqueología del futuro (Konnertz 1984, 91).

En los años 60 la obra de Paolozzi toma una nueva dirección: el artista se vuelve más interesado en formas arquitectónicas y de ingeniería que en criaturas más o menos figurativas. Sus formas son más geométricas y sus superficies son más lisas. El material que usa es el aluminio que es un material más barato y nuevo en su uso artístico. Una obra en este estilo es "The Twin Towers of the Sphinx, State I" (de 1962, perteneciente a una colección privada) aunque es una de sus últimas obras en bronce. A pesar de su aspecto arquitectónico, todavía sugiere figuras y estas tienen 
también algo de ese robot, de ese hombre-máquina que parece haber fascinado a Paolozzi desde siempre. Son esculturas que muestran el orden racional de la tecnología (Collins 2014, 139). Intencionadamente parecen objetos con una función pero no lo son, parecen motores que pueden funcionar, inventos que tienen un propósito, pero no son más que representaciones irreales que sugieren un mundo del futuro 0 un mundo onírico.

Posteriormente introduce esculturas con componentes tubulares, por ejemplo "Medea" (1964) en el Kröller- Müller Museum. El año antes de su creación Hollywood había producido la película "Jasón y los Argonautas". La escultura tiene un cuerpo geométrico con cuatro piernas-tubos que aluden a la Medea bailarina de la película y no a la hechicera del mito griego. Es significativo notar cómo Paolozzi se interesó por el mito de Jasón y Medea (recordemos la escultura "Jason") pero no a través de las propias fuentes clásicas sino a partir de unas recreaciones posteriores del mito -tanto en el cine como en el escenario- que introducía aspectos que no se encuentran en las fuentes antiguas.

Mientras Paolozzi fue profesor de escultura en Munich -ya en los años de 1980pasaba los domingos dibujando de la magnífica colección de escultura griega en su museo favorito: la Gliptoteca. Esto produjo el efecto de un regreso a la figura humana en su trabajo y de 1982 a 1984 realizó una serie de cabezas humanas. Más tarde fue invitado por el propio director de la Gliptoteca a organizar una exposición en Munich con sus alumnos mostrando cómo su trabajo interactuaba con las piezas antiguas del museo. El resultado fue una exposición que llevó por título "Entre héroes y dioses" donde colocó una versión de su obra "The artist as Hephaestus" ("El artista como Hefesto") -que veremos después- al lado de un kouros de mármol del siglo VI a.C.

El personaje del dios Hefesto-Vulcano era uno de los primeros ejemplos de un escultor arquetípico. La leyenda de Hefesto, que tenía dos sirvientes autómatas que trabajaban para él (Homero, Iliada 18. 376-377, 417-420), debió fascinar e inspirar a Paolozzi ya que entonces estaba tratando la figura humana más como un autómata que como una persona real. Paolozzi regresó a la figura mítica de Hefesto-Vulcano en 1998 cuando recibió un encargo para crear una figura gigantesca para la Central Square de Newcastle. Paolozzi hizo una figura de escayola fragmentada de unos 70 


\section{MONOGRÁFICO}

centímetros como modelo, pero la figura real fue de 7 metros que fue colocada finalmente en su lugar en el año 2000. La figura tiene un martillo de acero que recuerda el papel de Hefesto trabajando en la fragua y que forma parte de la iconografía tradicional de Hefesto. En 1999 Paolozzi realizó una escultura aún mayor para la National Gallery of Modern Art de Edimburgo.

En 1992 Paolozzi hizo una figura pequeña de Dédalo en escayola y madera. Está de pie en una pose similar a las figuras de Hefesto, con los brazos extendidos y las manos como si estuvieran dispuestas a coger algún objeto. La diferencia con los Hefestos es que Dédalo está colocado sobre una plataforma con ruedas que podría aludir, como afirma Judith Collins $(2014,285)$, a los carros usados en las fundiciones de bronce, una referencia al papel de Dédalo como escultor. Recordemos que Dédalo en el mito era asimismo inventor y constructor, el que construyó el célebre laberinto de Creta. Al año siguiente Paolozzi incrementó el modelo tres veces para crear un "Dédalo sobre ruedas" en bronce (en los jardines del Jesus College de Cambridge) que alarga sus brazos y agarra con sus manos una barra de metal. Ya en los años 50 Paolozzi había hecho un par de pequeños bronces sobre ruedas, de manera que no hace más que volver a modelos propios.

Una interesante obra que ya he mencionado y que aúna el personaje mitológico con el autorretrato es "El artista como Hefesto", una estatua de bronce creada en 1987. Representa una figura humana de pie que se supone que es un autorretrato del propio Paolozzi de 2 metros y $64 \mathrm{~cm}$. Tiene un pie avanzado como para caminar y sujeta en las manos dos objetos que parecen sierras afiladas y que también recuerdan el trabajo manual de Hefesto y del propio artista. La escultura fue encargada para decorar la fachada de un edificio de una empresa de Holborn en Londres y fue colocada en un nicho realizado expresamente para ella. En 1987 Paolozzi comenzó a explorar la idea del autorretrato cuando se le encargó un retrato de su amigo Richard Rogers. De ahí pasó a presentar dos autorretratos en la Royal Academy que incluían el "Retrato del artista como Vulcano" (Collins 2014, 276-277). En 2012 la escultura de "El artista como Hefesto" se retiró para ser después vendida en subasta. Como he dicho, está basada en un busto de Paolozzi que fue realizado en 1983 por Celia Scott y luego Paolozzi realizó su propio autorretrato sobre el molde basado en la obra de Scott. Lo interesante es la idea del escultor que trabaja sobre el hierro como un Hefesto mismo 
en la fragua. Paolozzi se imagina a sí mismo como ese artista-artesano que es a la vez el dios de la fragua y el propio resultado de su obra. Finalmente Paolozzi donó una versión en escayola de esta estatua a la Nacional Portrait Gallery de Londres.

\section{Conclusión}

Paolozzi es un artista original que no encaja bien con ningún grupo artístico concreto. Surrealista, Pop, pionero del "reciclado", fue prolífico en numerosos estilos y formas. Del Surrealismo tomó el método de encontrar objetos al azar para producir obras de arte pero su inspiración le viene de otros muchos sitios. Sus grandes esculturas parecen hombres convertidos en máquinas pero que no son ni hombres ni máquinas. Son reflexiones sobre los humanos y su situación.

Paolozzi recrea mitos antiguos y plasma otros modelos de su época que van a convertirse en mitos. De manera que crea un mundo mitológico complejo, un mundo de máquinas y monstruos de ciencia ficción, de robots que se convierten en un cíclope, un Jasón o un Dédalo. En él los mitos antiguos y modernos se funden, él recrea mitos y a la vez contribuye a crear otros. Zeus, el Cíclope o Hefesto son a la vez personajes de la mitología clásica, personajes lejanos en el tiempo, y son, a la vez, una máquina o un robot, de manera que se acercan a su propio mundo, incluso se transforman en el propio artista o el propio artista se transforma en uno de ellos. En definitiva, en Paolozzi el imaginario mitológico se puso al servicio de la sensibilidad moderna. A su vez nos muestra cómo la tecnología, los objetos tecnológicos y las materias industriales han pasado a formar parte del material del artista y se convierten en parte integrante de sus obras. Pero, en definitiva, esas figuras-robots, esas ruedas y máquinas, esos hombres autómatas no son lo que parecen porque no pueden funcionar, representan una idea, pero no son inventos para ser utilizados y que cumplan una función sino obras de arte. El novelista asociado a la New Wave of Science Fiction J. G. Ballard en una de sus conversaciones con Paolozzi describió al artista como casi el único en intentar mirar el mundo creado por la tecnología moderna de una forma semejante a la forma en la que Freud se aproximó a los sueños. 


\section{MONOGRÁFICO}

\section{Referencias}

Apolodoro (1985). Biblioteca Mitológica. Traducción de Margarita Rodríguez de Sepúlveda, Madrid: Biblioteca Clásica Gredos.

Bermúdez, D. (2011). Las monstruosidades del collage: hacia una teratología del siglo XX" en Piñol Lloret, Marta (ed.), Monstruos y monstruosidades, Bilbao:

Ediciones Sans Soleil, 309-338.

Buck-Morss, S. (2002). Dreamworld and Catastrophe: The Passing of Mass Utopia in East and West. MIT Press.

Bueno, Sonia - Peirano, M. (Coord.) (2009), El rival de Prometeo. Vidas de Autómatas ilustres, Madrid: Impedimenta.

Collins, J. (2014). Paolozzi, Surrey: Lund Humphries.

Durand, G. (1981). Las estructuras antropológicas del imaginario, Madrid: Editorial Taurus. Glaser, H. A. and Rossbach, S. (2011). The Artificial Human: A Tragical History, Nueva York: Peter Lang.

Highmore, B. (2011). Image-breaking, God-making. Paolozzi's Brutalism. October 136. MIT Press, Cambridge, Massachusets, 87-104. http://www.mitpressjournals. org/doi/abs/10.1162/0CT0_a_00052?journalCode=octo\#.WHDKkFPhDIU Homero (2004). Odisea. Traducción de José Luis Calvo, Madrid: Ediciones Cátedra. Jeanneret, M. (2001). Perpetual motion. Transforming shapes in the Renaissance from da Vinci to Montaigne, Maryland: The John Hopkins University Press.

Kang, M. (2011). Sublime Dreams of Living Machines. The Automaton in the European Imagination. Cambridge, Massachusets: Harvard University Press.

Kirkpatrick, D. (1970). Eduardo Paolozzi, Londres: Studio Vista.

Kitnick, A. (2011). The Brutalism of Life and Art. October 136, Spring 2011, pp. 63-86.

Konnertz, W. (1984). Eduardo Paolozzi, Colonia: Dumont Verlag. Losada, J. M. (Ed.) (2015), Nuevas formas del mito, Berlín: Logos Verlag. Meneguzzo, M. (2006). El siglo XX. Arte contemporáneo, Barcelona: Mondadori. Nelson, V. (2001). The Secret Life of Puppets, Cambridge, Massachusets: Harvard University Press.

Ovidio (2005). Metamorfosis. Traducción de Consuelo Alvarez y Rosa Iglesias, Madrid: Ediciones Cátedra. 
Paolozzi, E. and Alloway, L. (1963). The Metallization of a Dream, Londres: Lion and Unicorn Press.

Paolozzi, E. (1979). The Development of the Idea, Eduardo Paolozzi. Exhibition compiled by The Glasgow League of Artistas. Glasgow: University of St Andrews Selz, P. H. (1959). New Images of Man, New York, MOMA.

Schneede, U. M. (1971). Eduardo Paolozzi, Londres: Thames and Hudson.

Stonard, J. P. (2008). The Bunk Collages of Eduardo Paolozzi. The Burlington Magazine, April 2008, pp. 238-247. https://johnpaulstonard.files.wordpress. com/2012/12/paolozzi_bunk.pdf

Stonard, J. P. (2011). Used Future: The Early Sculptures of Eduardo Paolozzi. J W575 Paolozzi book11, pp. 16-37 https://johnpaulstonard.files.wordpress. com/2015/05/stonard_paolozzi_clark-exh.pdf 